\title{
Study on the Principle and Method of Process Design for NC Milling
}

\author{
Mei Tian \\ College of Mechanical Engineering, Jilin Engineering Normal University No. 3050 Kaixuan Road \\ Kuancheng District, 130052 Changchun China \\ 32593829@qq.com
}

Keywords: NC milling; Process design; Tool path; Programming method; CAXA

\begin{abstract}
In order to achieve the goals of optimizing NC programming, improving programming efficiency, using NC machine tools reasonably, it is necessary to analyze and research the technical problems of $\mathrm{NC}$ processing technology design, to make a preparation for $\mathrm{NC}$ machining. This paper mainly introduces the characteristics of processing design in NC machining and the key points of analyzing parts' processing technology in NC machining. It expounds the principles of processing design for NC milling and introduces the design method of NC machining process based on the case from CAXA manufacturing engineer that lays a solid foundation for improving the utilization rate of NC machine.
\end{abstract}

\section{Characteristics of NC Machining Process}

According to the analysis of a large number of processing examples, the main reasons for the failure of $\mathrm{CNC}$ machining process is considered as a result of the process of calculation and programming. The preparation of numerical control process and NC program must pay attention to every detail of the process. If the NC machining process design is not reasonable, often to increase the workload, and sometimes even to overthrow the heavy, resulting in some unnecessary losses. The process design for $\mathrm{NC}$ machining is an important link in the process of NC machining, processing is correct or not, related to the preparation of parts machining program correctness and rationality, the process is good or bad, directly affect the efficiency of NC machining quality and efficiency as well as the program. Characteristics of $\mathrm{NC}$ machining process: CNC machining process, the content is very specific, process design is very tight. CNC machining process and machining process of general machine tools, due to the use of CNC machine has few processing steps, required special tooling features less quantity, overcome the ordinary transmission process is weak, generally speaking, the content of NC machining process is more complicated than the content of ordinary machining process. From the point of view of programming, the processing procedure is more complicated than that of general machine tools; The numerical control process has the technology compound ${ }^{[1]}$. The NC machining, the workpiece in a fixture to complete the boring, milling, reaming, tapping and other processing, therefore, the NC machining process with complex characteristics, can also be said that the NC machining process of the traditional process in the process of "integration", which makes the number of special fixture parts processing required is greatly reduced and the clamping of parts number and turnover time are greatly reduced, so that the machining accuracy and production efficiency have been greatly improved.

$\mathrm{CNC}$ machining process design is the workpiece $\mathrm{NC}$ machining of the pre process preparation work, whether it is manual programming or automatic programming, the work must be completed before the program ${ }^{[2]}$. In order to improve the optimization of NC programming, programming efficiency, reasonable use of CNC machine tools, it is necessary for us to analyze and Research on the NC machining process design and other technical problems, in order to make the CNC machining technique preparation work before.

\section{Process Analysis of NC Machining of Parts}

Analysis on the Rationality of NC Machining of Parts. Review the reasonableness of NC machining; choose CNC machining content not to prevent the put fine timber to petty use, CNC 
machine down to general machine tools. When selecting and deciding on a part of the numerical control processing, does not mean that all of its processing content is wrapped, and may only be part of the numerical control processing [3]. We should choose the most suitable; the most need to carry on the numerical control processing the content and the process carries on the numerical control processing. Usually the rationality of the numerical control machining of parts is: Parts of the high complexity, high precision, multi variety and small batch production, the NC machining will obtain higher economic benefits; according to the different parts of the machine performance and the requirements of the different classification of $\mathrm{NC}$ machining parts, parts distribution of different types of processing in different types of machine tools, in order to gain a higher the production efficiency and economic benefits [4]. In order to improve the machining efficiency of NC machine tools, the large amount of machining of the parts should be done as far as possible in the ordinary machine tools.

Key Points of Process Analysis for NC Machining of Parts. Before NC machining, we must first make a careful analysis of the numerical control processing technology of the part drawing, and should focus on the examination and analysis from the two angles of the convenience and possibility of NC machining. For example: First of all, the paper analyzes the dimension data of the part drawing, and gives the principle of the convenience of programming; Secondly, analyze whether the structure of parts of the processing parts of the process is consistent with the characteristics of CNC machining; In the end, we should analyze whether the machining accuracy required by the parts can be guaranteed. In short, CNC machine tool parts should be according to the parts drawing comprehensive analysis, requirements to parts of the structure shape, size and technology, so as to determine the process and process of machining.

\section{Principles of Process Design for NC Machining of Parts}

Method for Dividing Parts Machining Process. 1) According to the tool used to divide the process; 2) According to the rough, finishing division process; 3) According to the processing parts division process.

In the process of the division, must see parts of the structure and process of the work piece, the installation and the function of CNC machine tools, machining content much number of installation and factory production and management situation and other factors, flexibility, rationality. Processing sequence arrangement should be based on the structure of the parts and the rough situation [5], as well as the importance of positioning and clamping installation to consider, focusing on the rigidity of the work piece is not damaged, in order to ensure the accuracy of the overall parts processing.

Principles of NC Machining Process Design for Parts Machining. The following principles should be followed in the process of NC machining of the parts:

1) The principle of maximum concentration and orientation of working procedure;

2) The principle of finishing after rough machining;

3) The principle of near back far, first face after hole;

4) The principle behind the first;

5) The principle of minimum number of calls;

6) The principle of the shortest way;

7) The principle of least segment;

8) The principle of linking the NC machining process and the common working procedure;

9) The principle of special circumstances for special treatment

Design Principles of the Tool Path for NC Machining of Parts. The tool path should ensure the accuracy and the surface roughness of the work piece to be machined. In order to ensure the surface roughness of the surface of the work piece surface, the final contour surface should be arranged for the last time; processing route should be as short as possible to reduce the empty travel time, in order to improve the processing efficiency; rational selection of milling or milling in milling process. Generally speaking, the NC machine tool adopts ball screw, the movement space is very small, so the advantage of the mill is more than the inverse milling; selection of machining 
route for machining deformation of work piece [6]. In the first installation and processing of multi channel process, the first arrangement of the work of the work piece is less rigid; reasonable design of the cutting tool and the direction of cutting out. Most people approach using one-way positioning method, positioning error to avoid backlash caused by transmission system. The tool and direction and route should be seriously considered, to minimize the machined trace; during the cutting process, the cutting tool can not interfere with the contour of the work piece.

So, in order to ensure the quality of the contour surface and reduce the trace of the tool, we should design the reasonable tool to cut in and cut out the position of the cutting tool and the cutting tool position in order to ensure the quality of the contour surface. Try to avoid the contour method to cut and feed into the middle of the stop [7]. Don't try to arrange the cutting in and cutting out or change the knife and pause in the continuous contour, so as to avoid sudden changes in cutting force caused by elastic deformation, surface scratch, scratch or stranded shape mutation of common defects resulting in smooth and continuous contour. As shown in Fig. 1:

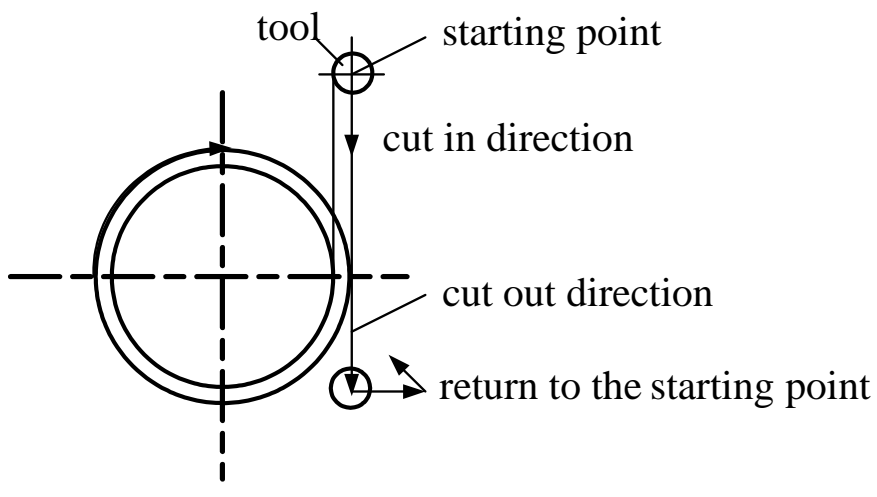

Figure 1. cutter path

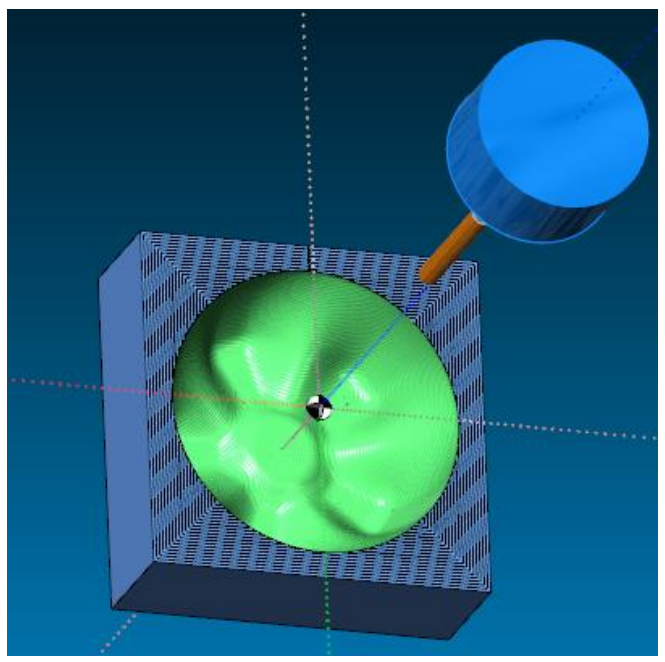

Figure 3. Simulation process

Cutting and cutting out the moving track of the cutter when milling the surface parts of the closed inner contour. Three processing routes of milling groove in Fig. 2: Figure A is used to process the groove, its processing route is the shortest, but the surface roughness is poor, it is suitable for rough machining or semi finish machining which is not too high for surface roughness. Figure B is a ring cutting method to process the groove, the surface roughness is the best, but the processing route is the longest [8]. Figure $\mathrm{C}$ is using the method of comprehensive processing groove, firstly using the cutting method for rough machining, the final contour with the ring cutting method and cutting a week along the contour is refined, the contour of the groove surface finishing, easy to ensure the surface quality of the groove side to the requirements. So figure $\mathrm{C}$ processing route scheme is the most reasonable [9].

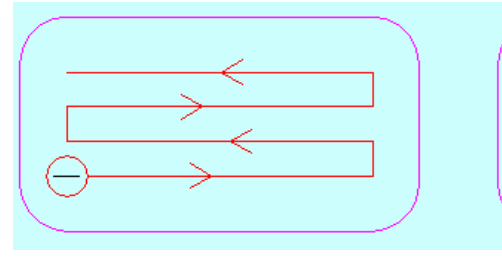

a

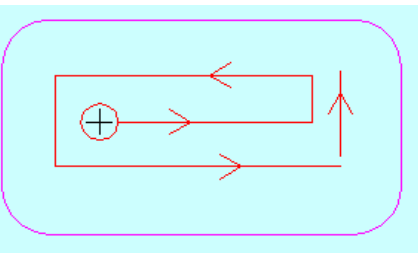

)

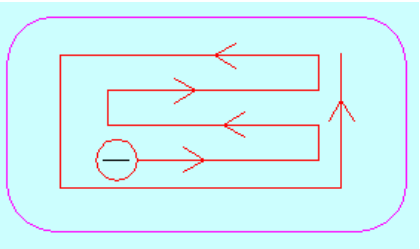

i 


\section{An example of coke bottle bottom machining based on CAXA Manufacturing Engineer}

The beverage bottle bottom as shown in Fig. 3, for example, the application of CAXA manufacturing engineer on the simulation processing. Blank material for plastic, the size is $80 \mathrm{~mm}$ $* 40 \mathrm{~mm} * 80 \mathrm{~mm}$, processing on the XD-40A CNC milling machine, ball milling cutter with $\phi_{8}$ cutter used for machining, the feed rate is $1500 \mathrm{~mm} / \mathrm{min}$, spindle speed is $1800 \mathrm{r} / \mathrm{min}$, the results of the optimization parameters are shown in table 1.

Table 1 Optimization results of process parameters

\begin{tabular}{|c|c|c|c|}
\hline & $\begin{array}{c}\text { processing time } \\
(\mathrm{s})\end{array}$ & $\begin{array}{l}\text { processing cost } \\
\text { (yuan) }\end{array}$ & $\begin{array}{l}\text { surface roughness } \\
\mathrm{R}(\boldsymbol{\mu m})\end{array}$ \\
\hline $\begin{array}{c}\text { before } \\
\text { optimization }\end{array}$ & 5286 & 67 & 0.68 \\
\hline $\begin{array}{c}\text { after } \\
\text { optimization }\end{array}$ & 5192 & 63 & 0.15 \\
\hline
\end{tabular}

Compared with the above data, processing parameters optimization, the completion time of all the process from the original 5286s to 5192s, the production efficiency has been improved. Processing costs from the original 67 yuan to 63 yuan, reducing the cost of processing. The surface roughness was reduced from $0.68^{\mu m}$ to $0.15^{\mu m}$, and the surface quality was improved.

\section{Conclusion}

Choose reasonable and efficient process and processing route, the preparation of high quality CNC machining program [10], improve the quality of parts, the production efficiency and economic efficiency of CNC machine tools are of great significance. The requirement of NC machining process design of design personnel is very high, not only need to understand CNC machining equipment and programming technology, but also must have rich knowledge of NC technology industry with and have rich practical experience. Only on this basis, the use of the correct design method, through careful and meticulous work, to complete the high quality CNC machining process design. In this way, in order to complete the machining of the parts on CNC machine tools, avoid unnecessary waste.

\section{References}

[1] Y.J. Chen and X.T. Chen: Modular Machine Tool \& Automatic Manufacturing Technique, (2013) No.3, p96.

[2] X.Zh. Zhao and J.L. Cheng: Numerical Control Processing Technology and Programming, Publishing House of electronics industry, BeiJing (2010).

[3] S.W. Zhang R.G. Zhang and W. Jia: Manufacturing Technology and Machine Tool, (2010) No.7, p.92-95.

[4] Q. Zhang and H. Wang: NC machine tools market, (2010) No.12, p.53-54. (In Chinese)

[5] C.H. Yu: Occupation, (2013) No.26, p.248.

[6] J.G. Yang, Y.Q. Ren, W.B. Zhu, M.L. Huang and Z.H. Pan: Chinese Journal of Mechanical Engineering, Vol. 39 (2003) No.3, p.81.

[7] J.F. Ji, L.S. Zhou, L.L. An and C. Zhang: Journal of Chongqing University, Vol.33, p.37. 
[8] B.Yan,A.P.Xu,D.W.Zhang and T.Huang: Chinese Journal of Mechanical Engineering, (2002) No.02, p. 160 .

[9] M.Q. Sun and Z.Y. Weng: Tool technology, vol.40 (2006) No.9, p7.

[10] R.Q. He, S.J. Yan and Y.F. Zhou: Machine Tool \& Hydraulics, (2006) No.9, p80. 